\title{
História da América Latina: diálogos possíveis entre a sociologia das ausências e os livros didáticos de História
}

\author{
History of Latin America: possible dialogues between the sociology of absences and \\ history textbooks
}

\section{Edson Antoni}

Doutor em História pela PUC-RS e Professor do Colégio de Aplicação da Universidade Federal do Rio

Grande do Sul

professor.antoni@gmail.com

\begin{abstract}
Resumo: Neste artigo analisamos os conteúdos de história latino-americana presentes em livros didáticos distribuídos às escolas brasileiras pelo Programa Nacional do Livro Didático (PNLD). À luz do entendimento da razão metonímica, é possível estabelecer uma análise acerca destes materiais didáticos e, consequentemente, compreender alguns elementos que dificultam a constituição de uma identidade latinoamericana. Com base neste estudo é possível perceber que, mesmo havendo referências à história latino-americana nas fontes selecionadas, a forma como esse conteúdo é apresentado contribui para a produção daquilo que definimos como a não-existência da experiência histórica latino-americana. Acreditamos que a dificuldade de constituir, a partir do Brasil, uma identidade latinoamericana, bem como, a perspectiva do latinoamericano como um sujeito outro, é resultado desse processo de formação que encontra nos materiais didáticos uma importante base de apoio.
\end{abstract}

Palavras-chave: América Latina; Razão metonímica; não-existência.

\begin{abstract}
In this article we analyze the contents of Latin American history present in textbooks distributed to Brazilian schools by the National Textbook Program. Considering the metonymic ratio, it is possible to establish an analysis about these textbooks and understand some elements that hinder the constitution of a Latin American identity. Based on the study, we realize that, even though there are references to Latin American history in the selected sources, the way this content is presented contributes to the production of what we define as the nonexistence of Latin American historical experience. The difficulty of constituting, from Brazil, a Latin American identity as well as the perspective of the latin american as another person is the result of this formation process which finds in textbooks an important support base.
\end{abstract}

Keywords: Latin America; metonymic ratio; non-existence. 


\section{Introdução}

É possível perceber, a partir de algumas publicações (CARRETERO, ROSA, GONZÁLEZ, 2007; GUIMARÃES, 2012; ROCHA, MAGALHÃES, GONTIJO, 2015), que os trabalhos acerca do ensino de história e temas relacionados direta ou indiretamente a este campo vem crescendo nas últimas décadas. Ao analisarmos esses estudos, contudo, acreditamos existir uma importante lacuna relacionada ao ensino de história latino-americana. Dentre todos os aspectos possíveis a serem analisados com relação à história latino-americana, dentro do contexto de educação escolar básica, neste artigo iremos nos concentrar no estudo de um elemento específico, qual seja, a presença da história da América Latina nos livros didáticos.

Consideramos, como objeto de nossa pesquisa, oito coleções de livros didáticos ${ }^{1}$ que foram distribuídas às escolas públicas brasileiras por meio do Plano Nacional do Livro Didático (PNLD), ${ }^{2}$ no triênio 2014-2016. A escolha destas oito coleções atendeu a um critério que buscou selecionar, dentro do universo de obras disponíveis, materiais que representassem os diferentes níveis de avaliação ${ }^{3}$ realizada pelo próprio PNLD.

Cabe destacar, ainda em caráter introdutório, que a análise que realizamos dessas obras didáticas possui como base uma perspectiva teórica que extrapola o campo do ensino de história e da educação. Assumimos, como referencial teórico para o nosso estudo, alguns dos pressupostos apresentados por Boaventura de Souza Santos em seus trabalhos relacionados a reflexões epistemológicas e ao modelo de racionalidade ocidental (SANTOS, 2002; 2014; 2019).

Tendo como base um projeto de pesquisa intitulado "A reinvenção da emancipação social", Santos caracterizou o modelo de racionalidade ocidental a partir

\footnotetext{
1 As referidas coleções são compostas por quatro livros cada uma, destinados aos estudantes do Ensino Fundamental II. Compõem o conjunto de obras didáticas selecionadas as seguintes coleções: Estudar história: das origens do homem à era digital (Editora Moderna); História nos dias de hoje (Editora Leya); Jornadas.hist (Editora Saraiva); Para viver juntos: história (Edições SM); Projeto Araribá: história (Editora Moderna); Projeto Radix: história (Editora Scipione); Projeto Teláris: história (Editora Ática); Saber e fazer história (Editora Saraiva).

2 O Plano Nacional do Livro Didático (PNLD) é uma política educacional de Estado que realiza a avaliação, compra e distribuição de livros didáticos para a escolarização básica pública em todo o Brasil.

3 Os livros didáticos passam por um processo de avaliação a fim de serem inseridos no PNLD. As coleções são avaliadas por especialistas com base nos seguintes blocos de indicadores: 1) Manual do Professor; 2) Componente Curricular História; 3) Proposta Pedagógica; 4) Formação Cidadã e 5) Projeto Gráfico. No "Guia de Livros Didáticos: PNLD 2014” é possível encontrar, na forma de um quadro síntese, uma visão geral das avaliações recebidas por cada uma das coleções. Para além desse quadro, o referido "Guia" também apresenta as considerações, em forma de resenha, para cada um dos itens avaliados.
} 
daquilo que denominou de razão indolente ${ }^{4}$. Segundo o autor, "A razão indolente subjaz, nas suas várias formas, ao conhecimento hegemônico, tanto filosófico como científico, produzido no Ocidente nos últimos duzentos anos" (Idem: 240). Esta matriz de pensamento, à qual Santos em outros trabalhos também se refere como "epistemologias do Norte", de saberes, não científicos e não europeus/ocidentais, são desprezados. Uma racionalidade na qual narrativas específicas são impostas como universais (totalizantes) em detrimento de outras formas de conhecimento que serão silenciadas e invisibilizadas. Dessa forma, conclui Santos, um conjunto grande de experiências sociais estão sendo desperdiçadas, promovendo "un epistemicidio masivo en los últimos cinco siglos, por el que se ha perdido una inmensa riqueza de experiencias cognitivas". (SANTOS, 2014: 48).

A invisibilidade desses outros saberes, podemos então afirmar, não está associada a uma pobreza ou escassez de experiências, mas sim a um processo complexo e consciente de produção de não-existência. Conforme destacou Santos,

Não há uma maneira única ou unívoca de não existir, porque são vários as lógicas e os processos através dos quais a razão metonímica produz a nãoexistência do que não cabe na sua totalidade e no seu tempo linear. Há produção de não-existência sempre que uma dada entidade é desqualificada e torna invisível, ininteligível ou descartável de um modo irreversível (SANTOS, 2002: 245).

O autor argumentava, em sua pesquisa, a partir da experiência de movimentos sociais invisibilizados. Acreditamos, contudo, que à luz da compreensão da razão metonímica e dos seus mecanismos de produção de não-existência, podemos estabelecer importantes considerações acerca das narrativas apresentadas pelos materiais escolares e

\footnotetext{
${ }^{4}$ Segundo Boaventura de Souza Santos, a razão indolente é composta por quatro pilares básicos: "a razão impotente, aquela que não se exerce porque pensa que nada pode fazer contra a necessidade concebida como exterior a ela própria; a razão arrogante, que não sente necessidade de exercer-se porque se imagina incondicionalmente livre e, por conseguinte, livre da necessidade de demonstrar a sua própria liberdade; a razão metonímica, que se reivindica como a única forma de racionalidade e, por conseguinte, não se aplica a descobrir outros tipos de racionalidade ou, se o faz, fá-lo apenas para as tornar matéria-prima; e a razão proléptica, que não se aplica a pensar o futuro, porque julga que sabe tudo a respeito dele e o concebe como uma superação linear, automática e infinita do presente". (SANTOS, 2002: 239-240)

5 "As epistemologias do Norte concebem o Norte epistemológico eurocêntrico como sendo a única fonte de conhecimento válido, seja qual for o local geográfico onde se produza esse conhecimento. Na mesma medida, o Sul, ou seja, aquilo que fica do 'outro' lado da linha, é entendido como sendo o reino da ignorância. O Sul é o problema; o Norte é a solução. Nesses termos, a única compreensão válida do mundo é a compreensão ocidental." (SANTOS, 2019: 25)
} 
como estes contribuem, sobremaneira, para a invisibilização da história latinoamericana.

Cabe aqui destacar que o objetivo deste trabalho não está relacionado a uma avaliação individual das diferentes coleções no intuito de estabelecer uma hierarquização entre as mesmas. Buscamos, todavia, demonstrar como os textos didáticos utilizados recentemente no Brasil, aproximam-se, em decorrência de suas características, das lógicas de produção de não-existência apontadas por Santos. A análise que propomos, ao identificar tais características nos materiais didáticos, poderá contribuir para o nosso entendimento acerca das limitações existentes em relação aos conhecimentos vinculados ao contexto latino-americano. Estabelecendo-se esse distanciamento em relação à história do restante do continente americano já na Educação Básica, por meio desses manuais escolares, percebemos a consolidação de uma perspectiva de história eurocentrada que, além de não nos permitir sermos autores da nossa própria história, resulta ainda no enfraquecimento do processo de constituição de uma identidade latino-americana.

\section{A produção de não-existência da América Latina nos livros didáticos}

Desde a segunda metade do século XIX é possível identificar a presença de conteúdos relacionados à história latino-americana tanto nos Programas de Estudos como nos materiais didáticos das escolas brasileiras (DIAS, 1997). Contudo, ao considerarmos algumas das análises já realizadas acerca do ensino de história latinoamericana no Brasil (BITTENCOURT, 1996; SILVA, 2004; DIAS, 2004; KALILALVES \& OLIVEIRA, 2011; CONCEIÇÃO \& DIAS, 2011), ou mais especificamente, sobre os conteúdos de história latino-americana nos materiais didáticos (VILLALTA, 1996; FERNANDES \& MORAIS, 2013), a denúncia de manutenção de uma narrativa eurocentrada em relação aos referidos conteúdos é uma das características mais marcantes.

Segundo Santos, a manutenção de uma perspectiva eurocentada pode ser compreendida como uma expressão da chamada monocultura do saber, parte constitutiva da razão metonímica e, consequentemente, produtora de não-existências. A referida monocultura "consiste na transformação da ciência moderna e da alta cultura 
em critérios únicos de verdade e de qualidade estética, respectivamente. [...] Tudo o que o cânone não legitima ou reconhece é declarado inexistente.” (SANTOS, 2002: 247). Estabelece-se, assim, uma forma de conhecimento que se compreende como totalizante e que irá se impor sobre as partes. Nesta perspectiva, uma única narrativa importa e possui relevância, e as demais narrativas são minimizadas ou mesmo silenciadas.

A prevalência de uma narrativa em detrimento de outras, como sugere a chamada monocultura do saber, talvez seja o aspecto mais evidente que possamos destacar ao iniciarmos a nossa análise dos livros didáticos. Numa análise quantitativa das produções didáticas, evidencia-se que os capítulos referentes à história latinoamericana $^{6}$ possuem pouquíssima participação no montante geral dos conteúdos apresentados pelas obras. Considerando como referencial o número total de capítulos das diferentes coleções, os conteúdos de história latino-americana não ultrapassam, em nenhuma das oito coleções, o correspondente a cinco por cento (5\%) do total de conteúdos apresentados. Acreditamos que tal dado, por si só, já permite antever o estabelecimento de um limite, de uma linha "tão básica quanto invisível” (SANTOS, 2019: 25) entre aqueles temas considerados como relevantes e universais (das sociabilidades e histórias metropolitanas, das epistemologias do Norte), daqueles outros temas que serão considerados menores, de pouca relevância (das sociabilidades e histórias coloniais, das epistemologias do Sul). A ênfase dada à história europeia em detrimento dos conteúdos relacionados ao contexto latino-americano, já neste primeiro aspecto de nossa análise, reforça a perspectiva de hegemonia de um "Norte epistemológico eurocêntrico como sendo a única fonte de conhecimento válido" (SANTOS, 2019: 25), a única forma de conhecimento que merece e será considerada como relevante no ensino da história.

Seguindo em nosso estudo comparativo entre a razão metonímica e os conteúdos presentes nos materiais didáticos de história, o segundo aspecto a ser analisado corresponde à chamada monocultura do tempo linear. Intimamente associada à

\footnotetext{
${ }^{6}$ Consideramos em nossa análise, com base na divisão de capítulos apresentada pelas diferentes coleções de livros didáticos, a existência de três grupos de conteúdo: a) História Geral; b) História do Brasil; c) História Latino-americana. As referidas coleções apresentam de forma dissociada a história brasileira da história latino-americana, sendo esta última representada, unicamente, pela história dos países de colonização espanhola.

7 Boaventura de Sousa Santos apresenta o conceito de "linha abissal" para analisar o distanciamento produzido entre o conhecimento moderno/ocidental e o conhecimento não-ocidental. Segundo o autor: "As epistemologias do Norte têm como premissa uma linha abissal que separa as sociedades e as formas de sociabilidade metropolitanas das sociedades e formas de sociabilidade coloniais e nos termos da qual aquilo que é válido, normal ou ético do lado metropolitano dessa linha não se aplica no seu lado colonial." (SANTOS, 2019: 24-25)
} 
monocultura do saber, a monocultura do tempo linear também se encontra presente, de forma bastante clara, nos referidos manuais. Conforme enunciado por Santos em seu artigo, a monocultura do tempo linear pode ser compreendida como:

a ideia de que o tempo é linear e que na frente do tempo seguem os países centrais do sistema mundial e, com eles, os conhecimentos, as instituições e as formas de sociabilidade que neles dominam. Esta lógica produz nãoexistência declarando atrasado tudo o que, segundo a norma temporal, é assimétrico em relação ao que é declarado avançado (SANTOS, 2002: 247).

$\mathrm{Na}$ análise dos livros didáticos, dois aspectos relacionados à perspectiva de organização linear e eurocentrada do tempo chamam a atenção. O primeiro diz respeito à divisão dos períodos históricos, enquanto o segundo está relacionado ao ordenamento e sequenciamento dos capítulos.

No que se refere à organização linear e a divisão quatripartite da história, é possível identificar um comportamento bastante similar nas oito coleções de livros. Nos capítulos referentes à introdução dos conceitos históricos ${ }^{8}$, encontramos em sete coleções $^{9}$ observações ou críticas à tradicional periodização estabelecida pelos europeus: "Fique ligado! A divisão acima é bastante criticada pelos historiadores, pois leva em conta os fatos mais significativos da história da Europa, que nem sempre tiveram importância para os povos de outras regiões.” (VICENTINO, 2012: 18)

Portanto, ela não serviria para compreender todas as sociedades humanas, apenas as europeias. [...] Mais uma vez, fique atento: toda a periodização é produto de uma interpretação histórica. Ela é construída em função dos

\footnotetext{
${ }^{8}$ As oito coleções apresentam, como primeiro capítulo ou unidade do volume dedicado ao sexto ano, uma breve análise sobre alguns dos principais conceitos relacionados à produção do conhecimento histórico e ao ensino de história. Correspondem aos referidos capítulos ou unidades os seguintes títulos: "O que é História?” (Estudar História); “Que História é essa?” (Projeto Radix); "Por que estudar História” (Projeto Teláris); "Conhecer o passado" (Jornadas.hist); “Tempo e História” (Saber e fazer História); "Introdução aos estudos históricos" (Projeto Araribá); “A História, os seres humanos e o tempo" (História nos dias de hoje); "História: a humanidade no tempo" (Para viver juntos).

9 JORNADAS.hist é a única coleção que não apresenta qualquer observação ou crítica em relação à tradicional periodização quadripartite da História. A referida coleção simplesmente relativiza o advento da escrita como marco divisório entre a Pré-História e a História. "Muitos estudiosos não concordam com a denominação 'Pré-História', porque ela pode transmitir a falsa ideia de que a História começou apenas com o aparecimento da escrita, como se antes desse acontecimento as realizações humanas não fossem significativas. Além disso, eles argumentam que, mesmo após a invenção da escrita, muitos povos mantiveram um modo de vida baseado na tradição oral, ou seja, na transmissão de valores e conhecimentos por meio da fala e não da escrita." (PANAZZO \& VAZ, 2012: 50)
} 
critérios e interesses de quem a elaborou (COTRIM \& RODRIGUES, 2012: 21).

Nem todos os historiadores, porém, concordam com isso. Para muitos, essa periodização valoriza os fatos políticos e enfatiza acontecimentos que são importantes apenas para a história europeia. Agindo assim, não consideram a história de outras sociedades humanas como a dos povos da África ou da Ásia (BRAICK, 2011: 28).

Entre essas sete coleções, existe uma que, inclusive, nega de forma enfática a utilização da referida periodização ao afirmar que "Justamente por não contemplar as realidades históricas de muitos povos, evitamos utilizar essa divisão temporal nessa coleção. Ainda assim é importante conhecer essas marcações” (AZEVEDO \& SERIACOPI, 2012: 18).

Apesar dessas observações, que poderiam indicar uma perspectiva não tradicional no corpo das publicações, as oito coleções acabam, de forma geral e contraditória, utilizando a periodização que criticam na introdução. Inclusive na coleção Projeto Teláris, onde identificamos a crítica mais veemente em relação à periodização eurocentrada, a apresentação posterior dos conteúdos segue a mesma linearidade das demais. Com relação a este comportamento, apresentado pelas propostas de ensino de história representadas pelas publicações didáticas, Cintia Monteiro de Araujo afirma:

De maneira mais ou menos geral, as propostas mantêm um padrão cronológico linear de organização dos conteúdos, onde prevalece uma concepção de tempo eurocêntrica como única possibilidade de organizar o processo histórico. Ainda que, ao final da década de 1980 e no início da década seguinte, tenham surgido propostas que apresentassem formulações alternativas, a sólida tradição escolar, que se apoia na utilização da cronologia quadripartite de origem francesa, não foi rompida. (ARAUJO, 2013: 266-267)

Em consonância com a hipótese que defendemos ao longo deste artigo, e em sintonia com a fundamentação teórica proposta por Boaventura de Sousa Santos, a referida autora também entende que: "A permanência desse modelo para o ensino de História, que se mantém dominante desde o século XIX, parece-me revelar bem mais do que uma característica própria da epistemologia do saber histórico escolar. A tradição 
cronológica linear na organização dos conteúdos indica, na minha opinião, relações de colonialidade que aí subsistem”. (ARAUJO, 2013: 270)

O segundo aspecto presente nos livros didáticos que podemos associar à monocultura do tempo linear está relacionado, conforme já apontado, ao sequenciamento e ao estabelecimento de cronologias a partir do ordenamento dos capítulos dentro das diferentes coleções. $\mathrm{Na}$ análise realizada em relação ao ordenamento dos capítulos, duas características foram destacadas. A primeira foi o fato de que em apenas uma coleção (Projeto Radix) os conteúdos relacionados às civilizações meso-americanas (dentre as quais estão maias, astecas e incas) são apresentados junto ao período de formação e organização das demais civilizações da África (egípcia) e da Ásia (mesopotâmica, hebraica, fenícia e persa). Nas outras sete coleções, esse capítulo da história latino-americana somente será apresentado após o capítulo destinado às chamadas grandes navegações ou à expansão marítimo-comercial ibérica.

Ainda com relação ao ordenamento de capítulos e à elaboração de uma narrativa que assume a cronologia europeia como elemento orientador, outro aspecto identificado pela pesquisa está relacionado aos conteúdos da história latino-americana referentes ao século XX. Ainda que a história latino-americana do período seja apresentada pelas diferentes coleções, e a partir de distintas abordagens ${ }^{10}$, em nenhuma das narrativas o contexto latino-americano é apresentado com algum protagonismo. A análise superficial de aspectos isolados da história latino-americana no transcurso de todo o século XX, a partir de seções de capítulos, é a opção da maioria das coleções. Nesses casos, não existe o estabelecimento de uma narrativa que vincule os diferentes acontecimentos da história latino-americana entre si. Ao invés de responderem a uma tentativa de compreensão do processo histórico próprio do contexto americano, os episódios selecionados aparecem meramente como informações complementares às narrativas centradas na história europeia e/ou norte-americana.

\footnotetext{
${ }^{10}$ É possível identificar, na maioria das coleções, a predominância de duas abordagens com relação aos conteúdos da história latino-americana no século XX: a) conteúdos dispersos em seções de capítulos (Jornadas.hist; Saber e fazer História; Projeto Araribá; Estudar História); b) conteúdos reunidos em um único capítulo (História nos dias de hoje; Projeto Radix). Na coleção "Para viver juntos" encontramos referência à história latino-americana no título de dois capítulos (Populismo na América Latina; A América Latina na Guerra Fria), presentes no livro destinado ao nono ano. Cabe destacar que nestes capítulos, fato que não é característica dos demais volumes da coleção, os conteúdos relacionados à América Latina dividem espaço com alguns conteúdos de história do Brasil. Na coleção "Projeto Teláris", o conteúdo referente à América Latina no século XX é restrito a um subitem intitulado "A "crise dos mísseis' em Cuba". Apresentado no livro do nono ano, este conteúdo compõe a seção intitulada "A União Soviética e a Guerra Fria", dentro do capítulo "A Guerra Fria e a expansão do socialismo".
} 
Faz-se relevante ainda destacar o comportamento de outras duas coleções em relação a este período histórico. Nestas coleções (Projeto Radix e História nos dias de hoje), todos os acontecimentos selecionados da história latino-americana do século XX são condensados em um único capítulo, no livro indicado para o nono ano. Neste caso, aproximadamente cem anos de história latino-americana são abordados com base na seleção de alguns poucos episódios que, afora a análise superficial, encontram-se em muitos casos dissociados entre si e de outros acontecimentos da história mundial. Nesses dois casos, os anacronismos que caracterizam os relatos acerca do contexto latino-americano ficam bastante evidentes. Na coleção "Projeto Radix", por exemplo, após um capítulo de história do Brasil no qual o texto apresenta uma narrativa que se estende da década de 1940 até o processo de redemocratização da década de 1980, o capítulo referente ao contexto latino-americano inicia com a análise dos processos de independência da América Latina ${ }^{11}$ ainda no século XIX. Com relação à coleção "História nos dias de hoje", o conteúdo que abre o capítulo referente à América Latina está relacionado à Revolução Mexicana de 1910. O referido contexto é apresentado após um capítulo que aborda a história brasileira entre as décadas de 1940 e 1950.

O ordenamento dado a esses conteúdos de história latino-americana, seja em relação às civilizações meso-americanas ou mesmo aos acontecimentos do século XX, em nosso entendimento reforça a perspectiva de uma narrativa eminentemente eurocentrada. Enquanto o tratamento dispensado às civilizações meso-americanas parece atender muito mais às necessidades de compreensão do processo de invasão e conquista europeia, os episódios do século XX não são tratados com relevância, permanecendo como conteúdos marginalizados em relação à narrativa de uma história eminentemente eurocentrada.

Somando-se às monoculturas do saber e do tempo linear, a lógica da classificação social é o terceiro elemento apontado por Santos na constituição da razão metonímica. A referida lógica, atuante no processo de produção de não-existência, pode ser compreendida a partir da "distribuição das populações por categorias que naturalizam hierarquias. A classificação racial e a classificação sexual são as mais salientes manifestações desta lógica" (SANTOS, 2002: 247).

\footnotetext{
11 Cabe destacar ainda que, no livro destinado ao último ano do Ensino Fundamental, é feita uma consideração acerca daquilo que será compreendido por América Latina. "Por América Latina entendemos o conjunto de países do continente americano colonizados por povos europeus de língua latina, sobretudo espanhóis e portugueses, a partir do século XV. Mesmo após as diversas ondas migratórias iniciadas no século XIX, essas nações continuaram mantendo características culturais e identidades comuns adquiridas durante o processo de colonização". (VICENTINO, 2012 :217)
} 
Uma vez mais, os aspectos enunciados como partícipes desse processo de marginalização e invisibilização de histórias e grupos caracterizam os manuais escolares. É possível identificar, em diferentes abordagens realizadas pelos livros didáticos, a contribuição destes para a constituição dos princípios de hierarquização social e de gênero.

Iniciamos nossa análise acerca dessa temática tomando como referência o caso de uma das coleções que nos parece bastante emblemático. Na coleção "Viver juntos", no livro destinado ao sétimo ano, é possível identificar a reprodução pura e simples de uma perspectiva discriminatória e de pretensa superioridade racial dos conquistadores europeus em relação aos povos que aqui habitavam. Chama a atenção que, após esta abordagem preconceituosa, não é apresentado qualquer tipo de contraponto, não é estabelecida uma análise ou reflexão que problematize a narrativa. A perspectiva eurocentrada é, dessa forma, a única versão que possui espaço dentro do referido texto.

Para os conquistadores, os nativos viviam em uma sociedade 'inferior' à sua. Essa 'inferioridade' era um dos argumentos dos espanhóis para considerar a América sua propriedade. Passaram então a se apossar das riquezas e impor seus valores cristãos. Eles se sentiam na obrigação de 'salvar as almas' dos ameríndios, convertendo-os ao catolicismo (NEMI \& BARBOSA, 2012: 48).

Para além do exemplo descrito, e ainda dentro da análise acerca da classificação social, a narrativa apresentada pelos textos escolares sobre os povos originários também deve ser destacada. Nos livros didáticos, a diversidade cultural dos povos originários da América, salvo raras exceções ${ }^{12}$, é reduzida aos termos de indígenas, nativos ou ameríndios. As definições homogeneizadoras utilizadas pelos colonizadores no início do processo de conquista do território para designar os povos que aqui habitavam é assumida e reiterada pelos livros didáticos no transcurso do século XXI. Nas diferentes coleções inexiste, aparentemente, uma preocupação em estudar a diversidade cultural existente antes da chegada dos europeus, nem tampouco a diversidade cultural ainda hoje presente no território.

A exemplo do tratamento dado à história dos povos originários, a narrativa acerca das diferentes populações africanas que chegaram ao continente e ajudaram a

12 Apenas três coleções (Estudar História, Projeto Araribá e Projeto Radix) apresentam, em algum momento, elementos histórico-culturais diferentes daqueles relacionados às comunidades astecas, maias e incas. 
compor a sua história também está limitada nos textos didáticos. Na metade das coleções $^{13}$ analisadas não existem maiores referências à participação de população de africanos na composição das sociedades coloniais hispano-americanas. Ainda com relação à presença histórica destas comunidades, dentre as coleções que mencionam a presença de africanos, duas abordam o tema fazendo-o a partir de enunciados como "escravidão africana” (Estudar História) ou "escravos negros" (Jornadas.hist). Estudos indicam que a simples utilização de tal terminologia reforça uma interpretação a partir da qual a escravidão é apresentada como uma condição natural desses grupos humanos, e não como resultado de um processo histórico de conquista, dominação e escravização. (TAILLE \& SANTOS, 2012)

Entendemos, dessa forma, que o tratamento dispensado aos povos originários e africanos nos textos didáticos, além de promover a "naturalização da hierarquização" apontada por Boaventura de Sousa Santos, também pode ser compreendido dentro de um contexto mais amplo, representando a manutenção de um padrão racial na divisão das populações mundiais, estabelecido pela modernidade europeia. Com relação a este processo de estabelecimento de identidades e hierarquias raciais, Aníbal Quijano afirma:

A formação de relações sociais fundadas nessa idéia, produziu na América identidades sociais historicamente novas: índios, negros e mestiços, e redefiniu outras. [...] E na medida em que as relações sociais que se estavam configurando eram relações de dominação, tais identidades foram associadas às hierarquias, lugares e papéis sociais correspondentes, com constitutivas delas, e, consequentemente, ao padrão de dominação que se impunha. Em outras palavras, raça e identidade racial foram estabelecidas como instrumentos de classificação social básica da população. (QUIJANO, 2005: 117)

É possível identificar ainda um terceiro grupo social que não encontra representação expressiva na grande maioria dos textos didáticos analisados. Salvo raras exceções, as mulheres não são apresentadas como agentes históricos relevantes, tendo a sua participação social invisibilizada. Das oito coleções analisadas, somente três (Projeto Radix, Viver juntos e Estudar História) reservam algum espaço de destaque à

\footnotetext{
${ }^{13}$ As quatro coleções nas quais a população de africanos não é apresentada como formadora da sociedade colonial hispano-americana são: Projeto Teláris; Viver juntos; Saber e fazer História; História nos dias de hoje.
} 
atuação das mulheres em processos históricos. Nas duas primeiras, no livro indicado para o oitavo ano, encontramos relatos acerca da participação de mulheres nos processos de independência das antigas colônias espanholas na América ${ }^{14}$, enquanto a última, no livro destinado ao nono ano, comenta a participação das mulheres no processo da Revolução Mexicana ${ }^{15}$. Sem promover um estudo mais detalhado da participação de mulheres nos processos históricos na América Latina, a narrativa apresentada na maioria das coleções mantém o seu foco na atuação de figuras consideradas como mais expressivas, majoritariamente masculinas.

A chamada lógica da escala global é o quarto aspecto destacado por Santos na sua análise acerca da razão metonímica. Conforme o autor, "nos termos desta lógica, a escala adotada como primordial determina a irrelevância de todas as outras possíveis escalas. Na modernidade ocidental, a escala dominante aparece sob duas formas principais: o universal e o global." (SANTOS, 2002: 248). Com base nos pressupostos apresentados pela lógica da escala global, é possível compreender que alguns acontecimentos ou valores, que estariam associados inicialmente ao contexto europeu, assumam uma condição de fenômenos de relevância universal, ao passo que outros, não relacionados a este mesmo contexto, serão tratados unicamente como manifestações locais e regionalizadas, não recebendo, por conseguinte, a mesma atenção.

Novamente, a partir de diferentes narrativas, é possível reconhecer nas produções didáticas analisadas alguns elementos que aproximam os referidos textos da interpretação antes apresentada. Acreditamos que um exemplo que pode ser apontado como característico desta definição de escalas é a prevalência dos conteúdos referentes aos aspectos culturais da Europa. As descrições de elementos culturais referentes às sociedades grega e romana no período da Antiguidade, bem como das sociedades europeias do período medieval até a Idade Contemporânea, são apresentadas de forma destacada em grande parte das coleções. Valores e princípios estéticos europeus são

\footnotetext{
14 Ainda que as coleções "Projeto Radix" e "Viver juntos" tratem da participação feminina no mesmo processo histórico, citando, inclusive, a mesma bibliografia acadêmica, é importante destacar que somente na segunda coleção encontramos referências nominais às mulheres que tomaram parte nas lutas pela independência. Em uma seção, ao final do capítulo, intitulada "Dossiê", a coleção "Viver juntos" apresenta um número significativo de citações extraídas do texto de Maria Lígia Coelho Prado (A participação das mulheres nas lutas de independência política da América Latina) a partir das quais é possível reconhecer a atuação de mulheres em diferentes regiões do continente.

15 Utilizando-se de uma seção ao final do capítulo, intitulada "Amplie seu conhecimento", a coleção "Estudar História" também irá abordar a atuação das mulheres dissociada da narrativa histórica principal. A participação das mulheres será apresentada por meio da figura literária de Adelita que, segundo o próprio texto, passou a representar genericamente as mulheres (soldaderas) participantes da Revolução. O texto destaca o papel cultural desempenhado por esta representação da figura feminina.
} 
apresentados em capítulos específicos, ao longo dos diferentes volumes que compõem cada uma das coleções. $\mathrm{Na}$ análise desses capítulos é possível perceber que os conteúdos referentes à cultura europeia são exaltados, tendo as suas principais características destacadas como elementos positivos e importantes no processo de constituição dos valores culturais universais ${ }^{16}$.

Comparativamente, o mesmo destaque não é dispensado às manifestações culturais latino-americanas. Afora as referências apresentadas nos capítulos correspondentes às antigas civilizações mesoamericanas, em nenhum outro serão destacados aspectos da cultura latino-americana. As poucas referências ${ }^{17}$ existentes estão relacionadas, basicamente, a pequenos textos que introduzem atividades complementares ao final dos capítulos.

Considerando-se ainda o estabelecimento de diferentes escalas em relação ao estudo da história, o processo de formação dos estados nacionais também pode ser apontado como um exemplo representativo. Enquanto observamos a descrição pormenorizada dos diferentes processos de constituição dos estados nacionais europeus (Portugal, Espanha, França, Inglaterra, Alemanha e Itália), assumindo claramente uma perspectiva de que a compreensão destes é de importância universal, as independências na América Latina são tratadas de forma concisa, e em blocos. A atenção dispensada ao contexto latino-americano, uma vez mais recebe um tratamento no qual a sua condição periférica fica evidenciada. A história do continente, novamente, é limitada a uma experiência histórica regionalizada, de menor importância para o transcurso dos acontecimentos da história universal.

\footnotetext{
${ }^{16}$ Neste aspecto, poderíamos tomar como exemplo a descrição que as diferentes coleções realizam acerca do pensamento daqueles que são considerados como os principais filósofos iluministas. Nestes textos didáticos a descrição realizada dos princípios filosóficos iluministas assume um caráter triunfante e salvacionista, sendo estes apontados como princípios universais. Nestes mesmos textos, contudo, não encontramos uma análise mais aprofundada acerca do posicionamento destes mesmos filósofos com relação às suas percepções acerca dos povos não-europeus. Analisando o pensamento de Immanuel Kant, por exemplo, Ramón Grosfoguel afirma que, para este, "la razón trascendental no va a ser uma característica de todos los seres [...]. Para Kant, la razón transcendental solamente la tiene aquellos considerados "hombres". Si tomamos sus escritos antropológicos, vemos que para Kant la razón transcendental es masculina, blanca y europea (Kant, 2004b). Los hombres africanos, asiáticos, indígenas, sureuropeos (españoles, italianos y portugueses) y todas las mujeres (incluídas las europeas) no tienen capacidade de 'razón'." (GROSFOGUEL, 2007: 66)

${ }^{17}$ As coleções "Projeto Radix", "Para viver juntos", "Projeto Araribá" e "História nos dias de hoje" apresentam, unicamente, atividades complementares, acompanhadas de pequenos textos explicativos, acerca de elementos da cultura latino-americana relacionados à literatura e artes plásticas. As coleções "Jornadas.hist" e "Saber e fazer História" apresentam, tão somente, um exercício que se utiliza de pintura e música nos seus enunciados.
} 
Como último elemento apontado por Santos na constituição da razão metonímica e, consequentemente, produtora de não-existência, encontramos a chamada lógica produtivista. A referida lógica, segundo o autor, se "assenta na monocultura dos critérios de produtividade capitalista. Nos termos desta lógica, o crescimento econômico é um objetivo racional inquestionável e, como tal, é inquestionável o critério de produtividade que mais bem serve esse objetivo" (SANTOS, 2002: 248).

Para além da compreensão dos diferentes processos de desenvolvimento econômico no curso da história, o papel desempenhado pelas nações capitalistas centrais no atual contexto mundial corresponderá ao foco da nossa análise neste último ponto. A escolha dos conteúdos para avaliação deste item recaiu, portanto, nas análises que cada uma das coleções irá fazer acerca das duas ou três últimas décadas.

As oito coleções apresentam, como último capítulo do volume dedicado ao nono ano, um panorama das condições econômicas e sociais do mundo atual. Ao analisarmos os referidos capítulos, foi possível perceber que apenas duas coleções (Projeto Radix e Jornadas.hist) dedicaram um espaço específico para analisar o contexto latinoamericano. Ainda que os títulos de capítulos das diferentes coleções possam sugerir uma proposta de análise mais ampla, como por exemplo "Mundo Contemporâneo" (Estudar História), “A Nova Ordem Mundial” (História nos dias de hoje; Projeto Araribá) ou ainda "As faces da globalização" (Saber e fazer História), a grande maioria destas publicações ${ }^{18}$ não irá contemplar a atual situação econômica e social da América Latina no bojo destes textos. Portanto, face ao distanciamento geográfico e econômico dos grandes centros de decisão do capitalismo mundial, uma vez mais será possível perceber o processo de invisibilização do contexto latino-americano.

\section{Considerações finais}

A despeito de todas as transformações ocorridas nas últimas décadas, em relação às atividades pedagógicas e da incorporação de novas plataformas e soluções o livro

\footnotetext{
${ }^{18}$ Em seis coleções não encontramos seções de capítulos destinados ao contexto latino-americano. Dentro deste grupo, cabe destacar que, no livro destinado ao nono ano da coleção "Para viver juntos", em um subitem da seção intitulada "O poderia dos Estados Unidos", existe em um parágrafo a referência ao fortalecimento de movimentos sociais em decorrência da crise econômica e a ascensão de governos "ligados às causas populares" (272) na América Latina. Cita nominalmente quatro presidentes e a adoção de políticas antiglobalização.
} 
didático continua sendo, ainda hoje, um importante instrumento de apoio no desenvolvimento das atividades de ensino nas escolas. Reconhecido este importante papel no processo de ensino e aprendizagem dos estudantes, é de fundamental importância que tenhamos um olhar muito atento e academicamente crítico aos seus conteúdos.

À luz desta situação, o presente artigo buscou elaborar um estudo acerca da forma como os conteúdos relacionados à história latino-americana estão sendo apresentados nas referidas publicações. Sem qualquer pretensão de apresentar uma qualificação ou hierarquização das obras analisadas, o objetivo foi estabelecer uma reflexão acerca dos possíveis efeitos que a perspectiva adotada por estas publicações ao contexto latino-americano podem causar.

Utilizando o referencial teórico apresentado por Boaventura de Souza Santos, acreditamos que as abordagens presentes nos livros didáticos, recentemente utilizados no Brasil estejam contribuindo, em certa medida, para o processo de produção daquilo que definimos como a não-existência da história latino-americana. Os mecanismos enunciados por Santos que compõem a chamada razão metonímica, e que atuam no processo de silenciamento e invisibilização de experiências sociais pelo mundo, são encontrados e orientam as narrativas presentes nas páginas de nossos manuais didáticos de História. Dessa forma, ainda que brevemente enunciada nos livros didáticos, a história latino-americana encontra-se submetida a um cerceamento e apequenamento analítico que lhe reduz a uma condição de marginalidade. Ao analisarmos de forma mais atenta os conteúdos referentes à história latino-americana, bem como a sua relação com os outros episódios da história universal, é possível perceber que a Latino América encontra-se como uma "parte desqualificada, subalterna e coadjuvante" de uma narrativa predominantemente eurocentrada, a qual, por sua vez, se pretende uma "totalidade homogênea".

Portanto, a fim de promover uma melhor compreensão dos fenômenos históricos latino-americanos, é de fundamental importância uma profunda revisão não somente dos conteúdos, mas também da forma como estes são apresentados pelos manuais didáticos. É indispensável e inadiável descolonizar as narrativas acerca da história latino-americana. Este processo de descolonização implica uma (re)escrita desta história, e sob um prisma que contemple como base outros referencias teóricos. Ou seja: uma (re)escrita da história que parta de referenciais teóricos latino-americanos, para que 
possamos, a partir de uma perspectiva autóctone, refletir sobre a nossa própria condição histórica.

Nesse processo de reformulação dos materiais didáticos, acreditamos ser de fundamental importância a elaboração de novas perspectivas de análise, que apresentem possibilidades e espectros alternativos a cada uma das lógicas produtoras da nãoexistência latino-americana. Em contraposição à colonialidade do saber e do tempo linear (que privilegiam saberes e uma narrativa cronológica eurocentrada), é preciso desenvolver e apresentar, por exemplo, conteúdos acerca dos povos originários que não fiquem presos a um tempo passado, restringindo a sua existência ao período colonial da história latino-americana. É indispensável a elaboração de textos didáticos que, a partir das experiências e narrativas dos próprios povos originários, desenvolvam conteúdos que representem a sua imensa diversidade cultural, bem como o papel político-social que essas comunidades vêm desempenhando, desde um passado histórico até o tempo presente, nas diferentes regiões da América Latina.

Além do destaque aos povos originários, outros grupos sociais (igualmente excluídos das narrativas tradicionais) também deverão ganhar maior protagonismo nessa (re)escrita da história. A fim de combater a exclusão promovida pela lógica da classificação social imposta pela razão metonímica, mulheres e populações afrodescendentes deverão assumir o seu espaço de protagonismo político-social. A menção e a ponderada reflexão sobre a importante atuação destes grupos nas diferentes mobilizações sociais que ocorreram ao longo da história do continente é condição fundamental para a aceitação e credibilidade de eventuais e futuros materiais didáticos.

Da mesma forma, os aspectos que caracterizam os livros didáticos a partir de uma lógica de escala dominante e produtivista necessitam ser substituídos. Mesmo não correspondendo a uma área central do capitalismo, a história dos países latinoamericanos necessita ser analisada a partir de uma outra perspectiva, na qual haja o reconhecimento da conexão entre as realidades locais e o global. Nesse sentido, uma proposta de reformulação desses textos didáticos considerará um processo no qual os elementos locais serão analisados a partir de suas possibilidades e potencialidades regionais, inclusive como sistemas alternativos de produção, para que posteriormente possam ser compreendidos dentro de um novo processo de reglobalização contrahegemônica.

Acreditamos, portanto, na necessidade de promover um grande movimento no sentido de reformulação dos materiais didáticos de História disponíveis na Educação 
Básica. Defendemos uma perspectiva a partir da qual os materiais didáticos possam refletir uma forma de pensar e produzir conhecimento com base nas experiências que nos são próximas, a partir de coletivos sociais, artistas e intelectuais da América Latina, que promovam a (re)escrita de uma história que nos será própria, podendo contribuir, de forma bastante contundente, para o processo de formação de uma nova identidade latino-americana.

\section{Fontes}

AZEVEDO, Gislane Campos \& SERIACOPI, Reinaldo (2012). Projeto Teláris: História. São Paulo: Ática.

BRAICK, Patrícia Ramos (2011). Estudar história: das origens do homem à era digital. São Paulo: Moderna.

CAMPOS, Flavio de; CLARO, Regina; DOLHNIKOFF, Miriam (2012). História nos dias de hoje. São Paulo: Leya.

COTRIM, Gilberto \& RODRIGUES, Jaime (2012). Saber e fazer história. São Paulo: Saraiva.

NEMI, Ana Lúcia Lana \& REIS, Anderson Roberti dos (2012). Para viver juntos: história. São Paulo: SM.

PANAZZO, Silvia. \& VAZ, Maria Luísa (2012). Jornadas.hist - História. São Paulo: Saraiva.

PROJETO ARARIBÁ: HISTÓRIA (2010). São Paulo: Moderna.

VICENTINO, Cláudio (2012). Projeto Radix: história. São Paulo: Scipione.

\section{Referências bibliográficas}

ARAUJO, Cíntia Monteiro (2013). Uma outra história possível? O saber histórico escolar na perspectiva intercultural. In: PEREIRA, Amilcar Araujo. \& MONTEIRO, Ana Maria. (org.) Ensino de história e culturas afro-brasileiras e indígenas. Rio de Janeiro: Pallas: 265-285.

BITTENCOURT, Circe Maria F. (1996). O percurso acidentado do ensino de História da América. In: BITTENCOURT, Circe Maria F. \& IOKOI, Zilda Márcia Gricoli. (coord.) Educação na América Latina. Rio de Janeiro: Expressão e Cultura; São Paulo: EDUSP: 203-218.

CARRETERO, Mario; ROSA, Alberto; GONZÁLEZ, María Fernanda. (org.) (2007). Ensino da história e memória coletiva. Porto Alegre: Artmed.

CONCEIÇÃO, Juliana Pirola da. \& DIAS, Maria de Fátima Sabino (2011). Ensino de História e consciência histórica latino-americana. Revista Brasileira de História. São Paulo, vol. 31, n 62: 173-191, dez.

DIAS, Maria de Fátima Sabino (1997) A invenção da América na cultura escolar no Brasil. Tese (Doutorado em Educação) - Faculdade de Educação, Universidade Estadual de Campinas. Campinas- São Paulo.

DIAS, Maria de Fátima Sabino (2004) História da América. Ensino, poder e identidade. Florianópolis: Letras Contemporâneas.

FERNANDES, Luiz Estevam. \& MORAIS, Marcus Vinícius de (2013). Renovação da História da América. In: KARNAL, Leandro. (org.) História na sala de aula: conceitos, práticas e propostas. São Paulo: Contexto: 143-162 
GROSFOGUEL, Ramón (2007). Descolonizando los universalismos occidentales: el pluri-versalismo transmoderno decolonial desde Aimé Césaire hasta los zapatistas. In: GÓMEZ, Santiago Castro. \& GROSFOGUEL, Ramón. (comp.) El giro decolonial: reflexiones para uma diversidade epistémica más allá del capitalismo global. Bogotá: Siglo del Hombre Editores; Universidad Central, Instituto de Estudios Sociales Contemporáneos y Pontifícia Universidad Javeriana, Instituto Pensar: 63-77.

GUIMARÃES, Selva (2012). Didática e prática de ensino de História: Experiências, reflexões e aprendizagens. Campinas, SP: Papirus.

KALIL-ALVES, Thamar. \& OLIVEIRA, Wellington de (2011). O ensino de história da Aérica Latina no Brasil: sobre currículos e programas. MAGIS, Revista Internacional de Investigación em Educación. Bogotá: Pontifícia Universidad Javeriana, vol. 3, n. 6: 283-298, jan./jun.

QUIJANO, Anibal (2005). Colonialidade do poder, eurocentrismo e América Latina. In: LANDER, Edgardo (org). A colonialidade do saber: eurocentrismo e ciências sociais. Perspectivas latino-americanas. Buenos Aires: CLACSO: 117-142.

ROCHA, Helenice; MAGALHÃES, Marcelo; GONTIJO, Rebeca (org.) (2015). $O$ ensino de história em questão: cultura histórica, usos do passado. Rio de Janeiro: FGV.

SANTOS, Boaventura de Sousa (2002). Para uma sociologia das ausências e uma sociologia das emergências. Revista Crítica de Ciências Sociais. n. 63: 237-280, out.

SANTOS, Boaventura de Sousa (2014). Más allá del pensamento abismal: de las líneas globales a una ecologia de saberes. In: SANTOS, Boaventura de Sousa. \& MENESES, Maria Paula. (eds.) Epistemologías del Sur. Madrid: Akal: 21-66.

SANTOS, Boaventura de Sousa (2019). O fim do império cognitivo: a afirmação das epistemologias do Sul. Belo Horizonte: Autêntica Editora.

SILVA, Vitória Rodrigues e (2004). O ensino de história da América no Brasil. Diálogos. Maringá: DHI/PPH/UEM, v.8, n. 2: 83-104.

TAILLE, Elizabeth Harkot de la. \& SANTOS, Adriano Rodrigues (2012). Sobre escravos e escravizados: percursos discursivos da conquista da liberdade. III Simpósio Nacional Discurso, Identidade e Sociedade. Dilemas e Desafios na Contemporaneidade. Campinas: Programa de Pós-Graduação em Linguística Aplicada da Unicamp (IEL/DLA); Programa de Pós-Graduação em Estudos Linguísticos e Literários em Inglês da USP (DLM/FFLCH).

VILLALTA, Luiz Carlos (1996). O cotidiano das populações coloniais da América nos livros didáticos. In: BITTENCOURT, Circe Maria F. \& IOKOI, Zilda Márcia Gricoli. (coord.) Educação na América Latina. Rio de Janeiro: Expressão e Cultura; São Paulo: EDUSP: 219-235.

Artigo recebido em 2 de janeiro de 2021.

Aprovado em 18 de junho de 2021.

DOI: $10.12957 /$ intellectus.2021.57515 